\title{
Size of black patches and spots on the upperwing and underwing greater secondary coverts in selected feathers are not good indicators of age and sex in Cape Vultures Gyps coprotheres
}

\section{Mlungele M. Nsikani ${ }^{1,2}$, Josphine Mundava ${ }^{2}$ \& Peter J. Mundy ${ }^{2}$}

Centre for Invasion Biology, Department of Botany and Zoology, Stellenbosch University, Private Bag X1, Matieland 7602, South Africa

Department of Forest Resources and Wildlife Management, National University of Science and Technology, PO Box AC 939, Ascot, Bulawayo, Zimbabwe

*Corresponding author: mlungele@ sun.ac.za

http://dx.doi.org/10.4314/vulnew.v69i1.2

\begin{abstract}
Cape Vultures Gyps coprotheres have black patches on their upperwing greater secondary coverts and black spots on their underwing greater secondary coverts. These have been physically observed to differ with individuals. This study examined the effects of age in years and sex on the size of the patches and spots using computer feather image analysis of birds with known ages in order account for differences that pure observation alone could possibly miss. Despite statistical analysis of computer enhanced
\end{abstract}


imagery of micro detail the chosen plumage pattern failed to yield a reliable way to age and sex Cape Vultures. Annual moult is not expected in this species making the correlation of moult to age a muddle as it is also influenced by external factors such as captivity, stress, food, endocrine (sexual changes), and latitude. This study was limited by the lack of understanding of the exact moulting sequence of upperwing and underwing greater secondary coverts of the Cape Vulture, and as a direct result of this, analysis of the chosen plumage was maintained instead of the feather that is moulted in that particular year.

\section{Introduction}

Natural selection has favoured many species of birds to wear plumages of different colour patterns especially in the breeding versus non-breeding seasons, at different ages, and between sexes (Rohwer \& Butcher 1988). To accomplish such changes in plumage, birds must replace their feathers through moulting (Palmer 1972).

A young Cape Vulture Gyps coprotheres moults its contour and flight feathers after fledging primarily to replace the juvenile plumage. The moult in the family Accipitridae, of which Cape Vultures are a member, takes between 3 and 10 months to complete (Humphrey
\& Parkes 1959). Moulting also includes, but is not limited to, trauma (lost feathers) and even fractured flight feathers (Mundy et al. 1992). In the juveniles of many species, moulting of body feathers begins slowly, not long after fledging (Clark 2004).

Prior to the first moult, contour and flight feathers are pointed, and the effect of the sun's UV light results in fraying edges to reveal a more pointed feather (Welty 1964). After the first year moult, the new contour and flight feathers that emerge are rounded in shape. The wing will then have a mixture of new (rounded) and old (pointed) contour feathers, and this mixture is easily seen on the upperwing greater 
secondary coverts (Mundy et al. 1992). With each progressive moult the contours develop a central black patch and the feathers develop pale undersides (Mundy et al. 1992).

Each feather on the upperwing greater secondary coverts has a central black patch in it which Mundy et al. (1992) refer to as a "Cap'n Morgan eye patch". This feature is diagnostic and conspicuous of the species (Mundy et al. 1992). All individuals in the species have this feature and it is observed at different ages; appearing to change from an almost entirely black feather in first year birds (Figure 1) to white feathers with black patches in adults (Figure 2). The change in the size of the black patches can easily be observed when a juvenile is compared to an adult. Each feather on the underwing greater secondary coverts has a black spot that appears to change from an almost entirely black feather in first year birds (Figure 3) to white feathers with black spots or sometimes just white feathers in adults (Figure 4).

The adults clearly have smaller black patch/spots compared to the juveniles, which have almost entirely black feathers. Feathers in Cape Vultures mainly change their physical characteristics with progressive moults, and UV light plays a significant role in bleaching and fraying the feathers. The moulting of feathers and the differences in the sizes of the black patches in adults and juveniles give a theoretical basis to correlate the size of the black patches/spots with age. Theoretically, therefore, the size of the black patches/spots could be an indicator of the age of a bird.

Knowledge of age and sex are important in population studies as they inform the research of population dynamics (Hughes 1998). Both sexes of the Cape Vulture are alike in plumage (Mundy et al. 1992) and like all vultures of the genus Gyps, they appear to lack plumage characteristics or external features to distinguish between sexes (Xirouchakis \& Poulakakis 2008). This makes it very important to develop sexing techniques that can be applied in the field.

In this study we explored the possibility of using the size of the black patches on the upperwing greater secondary coverts and spots on the underwing greater secondary coverts to age Cape Vultures. We also explored the possibility of using the size of black patches on the upperwing greater secondary coverts and spots on the underwing greater secondary coverts to sex Cape Vultures. We used scanned images 
of the feathers and pixel levels in Adobe photoshop to profile the sizes of spots and patches and make comparisons among ages and between sexes.

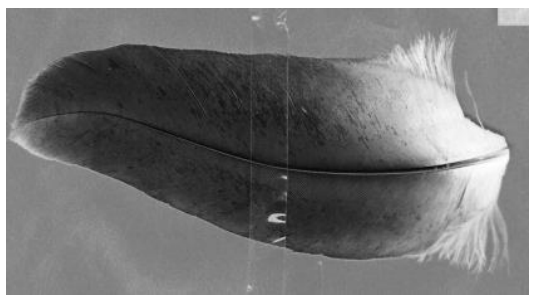

Figure 1: A first year's upperwing $1^{\text {st }}$ covert

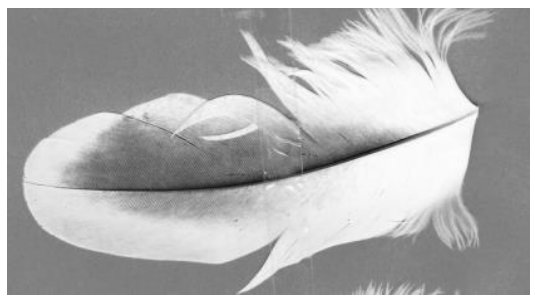

Figure 2: A nine year's upperwing $1^{\text {st }}$ covert

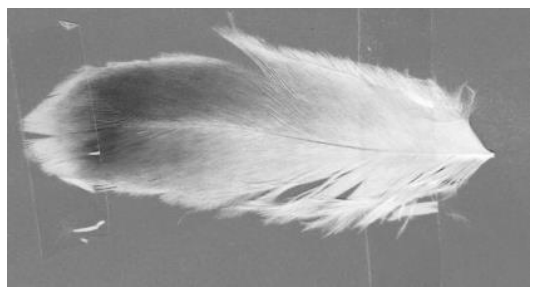

Figure 3: A first year's underwing $1^{\text {st }}$ covert

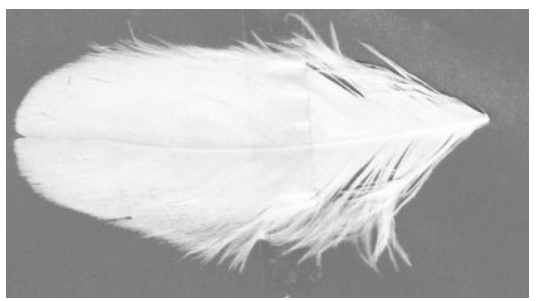

Figure 4: A nine year's underwing $1^{\text {st }}$ covert
Using computer-enhanced imagery of micro detail of the relevant plumage pattern was chosen in place of visual assessment in order to assess differences that pure observation alone could possibly miss.

\section{Materials and Methods}

Study site

The study was conducted at the Vulture Program's rehabilitation centre located in Rietfontein, just outside Hartbeespoort in the NorthWest Province of the Republic of South Africa $\left(25^{\circ} 42^{\prime} 7^{\prime \prime} \mathrm{S} ; 27^{\circ} 57^{\prime}\right.$ $2 " \mathrm{E})$. The centre is 9.4 hectares in area and it is situated on the southern foot of the Magaliesberg mountain range.

Selection of study birds

Individual birds with known ages were identified and selected from the database of the rehabilitation centre. A total of 19 birds with known ages were selected for study out of 108 Cape Vultures present at the centre at the time of conducting the study. The study birds were sexed according to the morphological characteristics of the head. Females have a narrow head (as seen from the lateral canthus of the eyes) with an egg- 
shaped dome at the top of the skull, while the males have a more triangular, flattened head with more prominent eye sockets (Mundy et al. 1992). The ratio of females to males was 15:4.

\section{Data collection}

A bird was captured and taken out of the enclosure. Its right wing was opened, and from the carpus (wrist) the first five feathers on the upperwing greater secondary coverts were identified. The $1^{\text {st }}, 3^{\text {rd }}$ and $5^{\text {th }}$ feathers were removed by careful cutting at the rachis using a lineman's pliers. The same procedure was done for the underwing greater secondary coverts. These feathers were selected because through physical observations they were the ones that showed the most differences with age of the bird.

The feathers were attached to blue A4 paper using clear sellotape and scanned using an HP scan jet 2200 c scanner at 300 dpi to generate images. The image of each feather was then analysed at pixel level in Adobe Photoshop CS3 10.0 in order to determine the sizes of the black patches and spots in proportion to the entire feathers. Blue paper was used in preference to white paper in order to reduce errors of pixel counting when analysing using Adobe Photoshop CS3 10.0. The steps in Adobe Photoshop CS3 10.0 are shown in Appendix A. A total of 114 feathers were measured: 57 on the upperwing and 57 on the underwing.

\section{Data analysis}

Data were tested for normality by plotting them against a normal plot; the resultant line deviated from the straight line indicative of normal distributions, therefore nonparametric analysis methods were used. A Kruskal-Wallis (KW) oneway analysis of variance by ranks was used to test for the effect of two explanatory variables (age and sex) on the mean proportion of the response variables (size of black patches and size of spots) on the upperwing and underwing greater secondary coverts. The data were analysed using SPSS version 16.0 and significance level was set at $\alpha<0.05$.

\section{Results}

The influence of age on the size of both the patch and spot yielded significant differences (patch: $K=$ 37.571, df $=6, \mathrm{p}<0.01$; spot: $K=$ 18.936, df $=6, \mathrm{p}<0.01)$. However, if the 1 year old birds were excluded 
from the analysis (in order to test whether the first year birds were mostly responsible for the differences), no significant differences were obtained for both the size of the patch and spot (black patch: $K=2.671, \mathrm{df}=5, \mathrm{p}=0.751$; black spot: $K=10.374, \mathrm{df}=5, \mathrm{p}=$ 0.065). The influence of sex on the size of both the patch and spot yielded insignificant differences (patch: $K=1.202, \mathrm{df}=1, \mathrm{p}=0.273$; spot: $K=0.334, \mathrm{df}=1, \mathrm{p}=0.563)]$.

\section{Discussion}

According to our results, we could only successfully use this technique to separate one year old Cape Vultures from other age groups. This is in line with the physical observations made during the study where the patches and spots of one year olds were the largest and the feather almost black. Similar observations were made by Mundy et al. (1992) where they noted that one year old birds had almost entirely black feathers on their upperwing greater secondary coverts and these changed to white feathers with black patches in adults.

One year old birds have plumage which is conspicuously different from sub-adults and adults (Mundy et al. 1992). The feathers on the upperwing and underwing greater secondary coverts are part of this plumage and this could explain the difference from the rest of the ages. A complete first moult occurs as the bird loses its juvenile plumage, and this moult is distinguishable; however, subsequent moults are varied (Mundy et al. 1992). Moults may sometimes happen or not happen to the feather in question. A few feathers may not be replaced every year, particularly among the upper tail or upperwing coverts and captive birds aren't expected to have the same moult patterns as compared to stressed wild birds (Clark, 2004; Pyle, 2005).

Wave moulting after the definitive first moult can be used to explain why the change in the size of the black patches did not show a clear pattern. This could have been caused by the feathers that were analysed were not the ones moulted by the bird that particular year. This explains why, for example, there was an increase in the size of the black patch at age five from age three. This change is infinitesimal as the overall effect of age is insignificant.

A complete understanding of the timing, sequence, and extent of moults is an essential aspect of the accurate ageing and sexing of birds and in the study of population 
dynamics (Newton, 1979). The same goes for immature raptors as knowledge and understanding of wave moult can ascertain the ages of immature raptors, in those species that take three or four years to attain adult plumage, as these species typically do not replace all of the primaries in any moult cycle (Clark 2004). Correlation of moult to age is a muddle and also influenced by factors such as captivity, stress, food, endocrine (sexual changes), and especially latitude. This study is limited in that there is no understanding of the exact moulting sequence of the upperwing and underwing greater secondary coverts of the Cape Vulture. Baseline information on the correct sequence of moult would have been useful in selecting and using the exact feathers exhibiting change in a particular year. Analysis of the $1^{\text {st }}, 3^{\text {rd }}$ and $5^{\text {th }}$ upperwing or underwing greater secondary coverts was maintained instead of the feather that is moulted in that particular year.

Sex does not have an effect on the size of the black patches and spots. This may be due to the physical differences in the size of the black patches and spots being caused by another factor which is not sexually dimorphic e.g. genetic variation. The two sexes are alike in plumage (Mundy et al. 1992).

\section{Conclusions}

Sex does not affect the size of the black patches and spots found on the upperwing and underwing greater secondary coverts in those feathers examined. Age has a similar negligible effect except when separating one year old birds from other age groups. However due to the limited use of feathers in the study, sexual dimorphism and differences with age may yet be identified with the use of a more complex array of feathers. Hence, making observations on more or all feathers on the upperwing and underwing greater secondary coverts using the same technique is highly recommended. The use of computer analysis to account for differences that pure observation alone could possibly miss is a valuable tool when dealing with more complicated and numerous variables, where human error is a real impediment and computer analysis an asset. 


\section{Acknowledgements}

The authors would like to thank data preparation, Hlengisizwe Ncube VulPro NPC for providing the for assisting with statistical analysis experimental units, Walter Neser, and the anonymous reviewers who Kerri Wolter and Obert Phiri for helped improve the quality of this assisting with data collection and work.

Keywords: moult, ageing, sexing, contour feathers, computer analysis

\section{References}

Clark, W. 2004. Wave moult of the primaries of accipitrid raptors, and its use in ageing immatures. In:Chancellor, R., D\& Meyburg, B. (eds). Raptors Worldwide. World Working Group on Birds of Prey and Owls, Berlin. pp. 795-804.

Hughes, C. 1998. Integrating molecular techniques with field methods in studies of social behaviour: a revolution results. Ecology 79: 383-399.

Humphrey, P. \& Parkes, K. 1959. An approach to the study of moults and plumages. Auk 76: 1-31.

Mundy, P., Butchart, D., Ledger, J. \& Piper, S. 1992. The vultures of Africa. Academic Press, San Diego.

Newton, I. 1979. Population ecology of raptors. T \& A.D Poyser, Berkhamstead (England).

Palmer, R. 1972. Patterns of molting. In: Farner, D., King, J. \& Parkes, K. (eds). Avian biology. Volume 2. Academic Press, New York. pp. 65-102.

Pyle, P. 2005. Remigial molt patterns in North American Falconiformes as related to age, sex, breeding status, and life-history strategies. Condor 107: 823-834.

Rohwer, S. \& Butcher, G. 1988. Winter versus summer explanations of delayed plumage maturation in temperate passerine birds. American Naturalist 131: 556-572.

Welty, J., C. 1964. The life of birds. Constable \& Co., London. 
Xirouchakis, S. \& Poulakakis, N. 2008. Biometrics, sexual dimorphism and gender determination of Griffon Vultures Gyps fulvus from Crete. Ardea 96: $91-98$.

\section{$\underline{\text { Appendix A }}$}

\section{Data preparation methodology in Photoshop}

- With Photoshop open, click 'file' on the top left hand corner

- Click 'new' to create a new workspace and this opens a box that asks how big the new image should be in pixels.

- To obtain the size of the new image the number of images scanned is multiplied by the dimensions of one image so that all the scanned images fit into one new image. This will batch process all the pictures

- The scan document is opened via Photoshop and all the feathers either for the upper or lower surface selected.

- To add the feather images to the work window, ' $\mathrm{Ctrl} \mathrm{A}$ ' in order to select all, followed by 'Ctrl C' to copy the feather images.

- 'ctrl V' will add the feather images to the work window, move the feather images into place so that all the scanned images fit into one image.

- Merge the layers by clicking on 'image' followed by merge 'layers'.

- Adjust the settings for image processing - 'Ctrl A' to select all images, then 'select', then 'colour range', then the blue part with the eye dropper to select it. The blue background is highlighted and the fuzziness set for 100 and tolerance to 80 .

- Click 'Inverse' to select the feathers only. Some background aspects may need to be removed to avoid distorting the calculations. Use the magic wand.

- 'Select' followed by 'inverse' again in order to select the background.

- The background is filled with the background colour blue by clicking on 'fill' and this leaves only the feather visible

- To best highlight the black patch/spot on the feathers, the image settings are placed at TOP 207 (output) and 180 (input), BOTTOM 15 (output) and 105 (input). 
- Each feather is selected using the selector, excluding the rachis and downy barbs at the base of the feather, because these parts of the feather are not being considered.

- The area around the feather is clicked using the magic wand whilst holding the 'Alt' sign. This results in the selection of the entire feather.

Refreshing the histogram gives the size of the feather in pixels. Zooming in, selecting 'colour range', clicking on the black patch/spot followed by 'ok' gives the size of the entire feather on the histogram.

$* * * * * *$ 